\title{
Literatur Lesen Lernen: Lesewerkstatt Deutsch 2
}

http://dx.doi.org/10.11606/1982-88372339213

\author{
Thiago Viti Mariano ${ }^{1}$ \\ Milena Wandembruck ${ }^{2}$
}

\section{Resenha de: EUBA, N.; WARNER, C.; DOBSTADT, M.; RIEDNER, R. (org.). Literatur Lesen Lernen: Lesewerkstatt Deutsch 2. Leipzig: Ernst Klett Verlag, 2017.}

Muito já se falou sobre os benefícios que a literatura pode trazer ao ensino de língua estrangeira moderna. Textos literários despertam maior interesse e motivação no aluno, propiciando uma aprendizagem mais interessante e prazerosa. Dentre suas diversas vantagens, a literatura destacase por possibilitar uma ponte entre a cultura da língua materna e a cultura da língua-alvo, além de permitir a expressão da voz do aluno em sala de aula, estimulando seu desenvolvimento social, emocional e cognitivo (KOPPENSTEINER 2012).

Conquanto a relevância do uso de literatura em sala de aula seja pouco questionável, a maneira como inseri-la suscita reflexões. Mais recentemente, Dobstadt (2009) propôs uma abordagem à inserção de textos literários no ensino de alemão como língua estrangeira (ALE) que busca atribuir à literariedade (JAKOBSON 1960) uma maior centralidade. Mais importante do que apenas fomentar a interação entre texto e aluno é trazer sua atenção à ambiguidade, multiplicidade e diversidade desse texto, que se encontra dentro de uma rede de diversos outros. O texto literário deve ser considerado, portanto, em sua dimensão poética, ideológica e cultural, e não apenas

\footnotetext{
${ }^{1}$ Universidade Federal do Paraná, Rua General Carneiro 460, $1^{\circ}$ andar, Curitiba, PR, 80060-150, Brasil. E-mail: thivima@gmail.com. ORCID: 0000-0002-5513-9718

${ }^{2}$ Universidade Federal do Paraná, Rua General Carneiro 460, $1^{\circ}$ andar, Curitiba, PR, 80060-150, Brasil. E-mail: milena.wdb@gmail.com. ORCID: 0000-0002-5941-5185
}

\section{(c) BY-NC}

Pandaemonium, São Paulo, v. 23, n. 39, jan.-abr. 2020, p. 213-218 
trabalhado a partir de seu conteúdo (SCHWEIGER 2015). Sendo assim, fala-se hoje de uma Didática da Literariedade, ou seja, da consideração dos aspectos estéticos de um texto, que são mais perceptíveis pelo leitor justamente em obras literárias. O uso estético da língua, que se expressa na materialidade do texto literário, assume, portanto, um caráter central no ensino de ALE através da literatura.

Nesse contexto, o livro didático Literatur Lesen Lernen Lesewerkstatt Deutsch 2, publicado pela editora Ernst Klett Sprachen, em 2017, de autoria de Nikolaus Euba e Chantelle Warner, organizado por Michael Dobstadt e Renate Riedner, traz como objetivo principal “aprender a ler literatura”. O material didático é direcionado para alunos de ALE a partir do nível linguístico independente B2, de acordo com o Quadro Europeu Comum de Referência para as Línguas (QCER), assim como para falantes de alemão como língua materna.

As propostas trazidas pelo livro são coerentes com a visão e entendimento de "língua" que os autores trazem na introdução, ou seja: língua entendida não como sistema de regras, mas como espaço para a liberdade e criatividade; língua que, através de uma abordagem criativa, permite a intensificação da própria voz e opinião do falante; língua que em sua complexidade nem sempre permite a apreensão de todas as possibilidades de significados existentes; língua que permite a convivência de diferentes interpretações e significados ao mesmo tempo; língua que possui forma, significado, ritmos e sons entrelaçados; língua que compõe uma rede simbólica de significados, do qual a literatura faz parte, colaborando para o melhor entendimento do mundo. Sendo assim, é possível dizer que as atividades propostas procuram tratar a língua a partir desses conceitos, de modo que o trabalho com literatura explore de maneira mais intensa as possibilidades de entendimento e significado que o texto literário tem a oferecer. Além disso, o desenvolvimento das propostas demonstra estar bem fundamentado, pois valoriza o texto literário em toda sua complexidade e fornece, tanto ao professor quanto ao aluno, ferramentas para uma experiência bastante enriquecedora no ensino e aprendizagem de língua alemã.

Cada um dos 10 capítulos do livro trabalha centralmente com um texto, mas propõe como atividade final uma extensão para outros textos complementares, que se relacionam ora com a temática, ora com os aspectos formais abordados. É importante ressaltar que o livro realiza propostas não só com obras literárias, como poemas, contos, crônicas, romances e drama, mas

Pandaemonium, São Paulo, v. 23, n. 39, jan.-abr. 2020, p. 213-218 
também com produções mais populares, como curtas-metragens, quadrinhos, best-sellers, fotografia e filmes de grande sucesso de bilheteria. Assim, são trabalhados também cartazes e roteiros de filmes, resenhas e críticas de filme e livro, capa e demais elementos para-textuais de um livro. Vale ressaltar também o trabalho com áudios e não só com a leitura de textos literários, com material publicitário, artigos de jornais, citações de entrevistas com autores, e comentários de leitores e espectadores em sites de internet. Porém, diante dessa gama de gêneros, pode-se questionar a falta de gêneros musicais.

Os capítulos seguem a mesma estrutura e apresentam em média 15 páginas, fazendo jus às 160 páginas do livro, que traz, além de uma introdução para apresentação de sua proposta geral, uma grande bibliografia dos textos utilizados e uma breve relação dos textos teóricos sobre os quais se embasa. Cada capítulo traz pelo menos uma imagem na página inicial como ilustração, sempre em preto e branco. É importante ressaltar que os capítulos não são enumerados, ou seja, há a possibilidade de se trabalhar com eles em qualquer ordem. Também é possível trabalhar apenas um capítulo individualmente, sem a necessidade de seguir todo o livro. No entanto, dentro de alguns capítulos há referência a outros que trazem propostas semelhantes, ou seja, os capítulos se relacionam. Para melhor entendimento do trabalho, os objetivos são sempre listados em itens denominados de pontos centrais, logo no início do capítulo, que mencionam os aspectos literários e linguísticos a serem enfatizados. Logo no início há, além disso, uma lista dos materiais a serem utilizados no capítulo, com referência às páginas onde se localizam ou com menção ao site da editora e código de acesso, no caso de vídeos e demais materiais on-line.

A parte denominada "Aprender a ler literatura" é onde de fato a didatização é explicada passo a passo para o professor, trazendo subtítulos variáveis para cada capítulo. Faz-se aqui a ressalva de que não existe um gabarito propriamente dito, tendo em vista a grande abrangência de possibilidades que o trabalho com literatura pode oferecer. Demais explicações sobre ao que se prestar atenção e como proceder para a aplicação das atividades também são elucidados nesta parte. Os capítulos trazem folhas de atividades prontas a serem copiadas para os alunos e aplicadas em sala, contendo tanto os textos literários em si quanto as atividades a serem realizadas. Há também ao final uma tabela-resumo com as etapas de cada fase da didatização e seus respectivos materiais e atividades.

Pandaemonium, São Paulo, v. 23, n. 39, jan.-abr. 2020, p. 213-218 
É importante se atentar para o fato de que o objetivo do livro é facilitar e estimular o trabalho com literatura, fornecendo instruções as mais claras possíveis sem, no entanto, retirar o espaço de liberdade e experimentação do professor, nem esgotar as possibilidades de trabalho. Os autores fazem a ressalva de que o objetivo não é domesticar o uso de textos literários para o ensino de língua e sim utilizá-lo como fim em si mesmo, de modo a trazer os alunos à leitura e reflexão. É por esse motivo que se deixa, sobretudo, aberto o espaço para demais possibilidades de trabalho que possam surgir com os textos propostos.

Cada didatização é composta de três fases. A primeira consiste em um confronto com o texto. O diferencial da abordagem proposta pelo livro é justamente a eliminação de tarefas anteriores ao texto, que facilitam a leitura. A justificativa é a de que o foco está em não retirar a atenção do aluno ao texto, às suas particularidades, permitindo assim o confronto com elementos que possam ser considerados estranhos, além de evitar o direcionamento para uma interpretação específica e minimizar o potencial de leitura do aluno.

A segunda fase consiste em uma intensificação do confronto do aluno com a obra e de seu trabalho de leitura e interpretação. Ao mesmo tempo, o objetivo é despertar o prazer na leitura e sensibilizar o aluno para as características literárias do texto. Dentre as atividades propostas, encontram-se: elaborar mapas mentais; responder a questões sobre aspectos formais e de conteúdo do texto ou imagem; discutir em grupos sobre determinadas características do material; elaborar um final para o texto; gravar a leitura do texto. Depois de atividades de reflexão e análise, o aluno é convidado à realização de tarefas de transformação, nas quais ele deve transportar acontecimentos, personagens e ações da obra para outro tipo de texto ou colocá-los sob outra perspectiva. Além disso, algumas atividades nessa fase permitem ao aluno entender o texto dentro de seu contexto espacial e temporal, culminando, portanto, num maior entendimento da obra, após a análise e interpretação. Dentre essas atividades encontram-se: fazer uma peça teatral, fotografias e filmes; redigir artigo de jornal e resenha; escrever um conto; escrever um texto sobre a própria experiência em relação ao tema; mudar a perspectiva usando outro narrador.

As atividades finais consistem basicamente em comparar o texto principal com os textos adicionais. $\mathrm{O}$ aluno é convidado a relacionar a obra trabalhada com demais obras. Essa expansão 
do conhecimento e trabalho desenvolvido é justamente a atividade final das propostas. Para o professor se abre também a possibilidade de expandir a temática através de materiais adicionais.

O primeiro capítulo indica um trabalho com o poema de Zehra Cirak, "kein Sand im Rad der Zeit”, que propõe ao aluno um exercício de alteridade, através de uma atividade de mudança de perspectiva. O segundo capítulo, um exercício a partir de "Die Tochter" de Peter Bichsel, com os elementos que constroem o conto (tempo, narração, espaço, personagem, enredo), assim como a exploração dos espaços vazios do texto, para que o aluno manifeste suas próprias impressões. Já o terceiro capítulo, propõe-se um trabalho com a história em quadrinho de Ulli Lust, "Terrarium”, incentivando o aluno a analisar mais profundamente as imagens e instigar seu espírito crítico. $\mathrm{O}$ quarto capítulo consiste no trabalho com os elementos que circundam a produção e o marketing do filme "vicent will meer" de Florian David Fitz, contemplando-se o roteiro, o trailer, as sinopses e as críticas. O capítulo cinco aborda o poema "Das Fremde aus der Dose" de Yoko Tawada, didatizando os efeitos poéticos que colaboram para o seu entendimento e para a reflexão a respeito do tema abordado, mostrando que forma e conteúdo não podem ser dissociados. No capítulo seis, trabalha-se com um trecho do livro "Tschick" de Wolfgang Herrndorf, permitindo o trabalho não só com literatura, mas também com a linguística, na abordagem de variabilidade de estilos. Os capítulos sete, oito e nove, respectivamente, trabalham com "Vor dem Gesetz" de Kafka, com "Materialien zu einer Kritik der bekanntesten Gedichtform italienischen Ursprungs" de Robert Gernhardt, "Die Leiden des jungen Werthers" de Goethe e com a versão "Die neuen Leiden des jungen W.” de Ulrich Plenzdorf. Assim, os temas abordados são, respectivamente: a estética do moderno; o uso de uma forma clássica como o soneto para expressão de um poema dos movimentos antiautoritários dos anos 1960; e releitura da obra mais famosa de Goethe no contexto da DDR. Por fim, o décimo e último capítulo aborda a construção do best-seller a partir do livro "Die Betrogene" de Charlotte Link, trabalhando os elementos para-textuais, e objetivando despertar o gosto do aluno pela leitura.

O livro Literatur Lesen Lernen” Lesewerkstatt Deutsch 2 oferece a professores e alunos as ferramentas necessárias para se trabalhar com textos literários em língua alemã de maneira inovadora e inspiradora. As atividades propostas são coerentes com os preceitos elucidados em sua introdução; o livro consegue conferir, de maneira convincente, maior centralidade ao uso

Pandaemonium, São Paulo, v. 23, n. 39, jan.-abr. 2020, p. 213-218 
Mariano, T.V.; Wandembruck, M. - Literatur Lesen Lernen

estético da língua, característica inerente à literatura, e instigar alunos a experimentar a língua de forma criativa, seja ela materna ou estrangeira. A publicação estimula, assim, a elaboração de materiais didáticos pluriformes, que renovem as possibilidades de ensino e aprendizagem.

\section{Referências bibliográficas}

DOBSTADT, M. „Literarizität“ als Basiskategorie für die Arbeit mit Literatur in DaF-Kontexten. Zugleich ein Vorschlag zur Neuprofilierung des Arbeitsbereichs Literatur im Fach Deutsch als Fremdsprache. Deutsch als Fremdsprache, Berlin, v. 46, n. 1, 2009, p. 21-30.

JAKOBSON, R. Closing Statements: Linguistics and Poetics. In: SEBEOK, T. A. (org.). Style in language. Cambridge: The MIT Press, 1960, p. 350-377.

KopPensteInER, J; SchwARZ, E. Literatur im DaF/DaZ-Unterricht: Eine Einführung in Theorie und Praxis (BachelorMasterStudies) Taschenbuch. Viena: Praesens Verlag, 2012.

SCHWEIGER, H; HÄGI, S.; DÖLL, M. Landeskundliche und (kultur-)reflexive Konzepte. Impulse für die Praxis. Fremdsprache Deutsch, Berlin, v. 52, 2015, p. 3-15. 